Nitrazepam and the Subconscious

SIR,-We must apologize for our delay in replying to the letter from Dr. Frances Taylor (13 January, p. 113) regarding her findings on the use of nitrazepam. As she mentioned, the drug may in certain cases give the patient vivid and painful nightmares, which disappear after a certain time. We were very pleased to hear her explanation on the lines of the good old Freudian theory of dreams and the psychotherapeutic effect of dreaming. Nitrazepam might thus be regarded as a catalyst, favouring the natura process of restoring psychic equilibrium.

This hypothetical statement should not be greeted with sumprise when we consider that nitrazepam belongs to the chemical class of the benzodiazepines, which are known to have the property of weakening the inhibiting power of the superego (please allow us to go on using the Freudian way of thinking and talking). But let us go further along the path that Dr. Taylor has opened up. It is generally accepted that most cases of insomnia are of psychic or psychopathological origin. This means that insomniacs are prone to a certain psyohic tension, which may be attributed to the subconscious persistence of unhealed psychic traumata or unresolved psychic conflicts. The reason for this persistence could be sought in the presence of an overdeveloped superego, which acts as such a strong repressive factor that inner traumata and conflicts cannot even reach the level of near-consciousness that we call dreaming.

If nitrazepam does allow distressing subconscious processes to enter into the field of dreams, it may enable patients to overcome their subconscious troubles. Consequently nitrazepam would act as a curative and not only as a symptomatic drug. Nitrazepam should thus liberate insomniacs from their insomnia for good. Hence the following simple practical suggestion to Dr. Taylor and to everyone who is interested in this matter: continue your nitrazepam treatment until excessive dreaming (whether reaching the painful intensity of nightmares or not) has disappeared and then stop it. If the Freudian theory of dreams and our ideas about nitrazepam are right, you might observe that in some cases there is no further need for any sleeping pill.-We are, etc.,

Antwerp

TONY Goossens

Brussels, Belgium

\section{MARCEL BUICKAERT}

ERIC WAKELING

\section{Discriminant Valve of Thyroid Function} Tests

SIR,-I should like to make the following comments on the paper by Dr. D. B. Barnett and others (21 April, p. 144).

The authors have neglected the fundamental difficulty in diagnostic medicine of defining in unequivocal terms the criteria which they propose to use to define the disease whioh they are trying to identify. Their only comment on this problem is to state that "on completion of all investigations the patients were allocated to three populations (thyrotoxic, euthyroid, or hypothyroid) by two doctors who collated all the test parameters." They then proceed to evaluate the discriminant value of these same parameters in arriving at the correct diagnosis. The possibility of bias by the two doctors must be self-evident.

I would also object to the description of the diagnostic methods recommended in the papers of Crooks et al. ${ }^{1}$ and Billewicz et al. ${ }^{2}$ as "clinical questionnaires" since they, in fact, attempted to apply statistical techniques to conventional clinical observations with only minimal, though important, constrictions on the method of obtaining the information.

Though I accept the conclusions of the authors that the combination of serum protein-bound iodine and triiodothyronine uptake tests is at present the most effective routine laboratory-based method of arriving at the diagnosis of thyrotoxicosis, I regre their implied denigration of clinical evidence as part of the diagnostic process. I also regret that they did not include the result of a therapeutic trial of the various methods of treating thyrotoxicosis in their paper since, in terms of the practicality of patient care this is a more acceptable diagnostic criterion than that provided.-I am, etc.,

JAMES Crooks

Department of Pharmacology and Therapeutics,

University of Dundee

1 Crooks, J., Murray, I. P. C., and Wayne, E. J. 2 Billewicz, W. Z., et al., Quarterly fournal of Medicine, 1969, 38, 255 .

\section{Administration of Disodium Cromoglycate to Young Children}

SIR,-The role of disodium cromoglycate (DSG) is now well established in the pro phylaxis of asthma. However, few children under the age of 3 to 4 years are able to use adequately the Spinhaler. We have now used for several years a simple and effective method of administering this drug to these young children. Ten milligrammes of DSG is dissolved in $2 \mathrm{ml}$ of saline and inhaled as a mist via a face mask and Bennett twin-jet nebulizer which is driven by an air compressor pump with an output of $6 \mathrm{l} / \mathrm{min}$. The drug is given three or four times a day and usually $0.25 \mathrm{ml}$ of $2 \%$ orciprenaline is included in the inhalation. Children readily adapt to this method as they can play or look at books during the 10-15 minutes of treatment.

So far 21 patients, all with moderately severe asthma clinically, have been treated Five under the age of 1 year did not receive any obvious benefit, but most of the others seemed to be helped. It has not been possible to obtain objective measurements of improved pulmonary function in these children because of their age, and a controlled trial was not conducted. Our clinical impression was that the frequency and severity of the wheezing episodes in the children over 1 year were much reduced after the introduction of DSG to the therapeutic regimen. Most of the children were having inhalations of orciprenaline alone before starting treatment with DSG. In only two of the 21 has corticosteroid treatment been necessary. Before starting DSG we felt that the majority of these patients would need long-term corticosteroids.

We would suggest that nebulized DSG is a useful therapeutic agent in children with asthma aged from 1 to 4 years as they cannot adequately use a Spinhaler. A controlled trial of its use is clearly indicated.

The DSG powder was supplied by Messrs. Fisons (Australia) Pty. Ltd. -We are, etc.

HoWard E. WILLIAMS Peter D. Phelan

\section{Clinical Research Unit,}

Royal Children's Hospital,
Melbourne, Australia

\section{Purpura Associated with Vomiting in Pregnancy}

SIR,-We recently encountered an unusual association between purpura and vomiting in pregnancy.

The patient was admitted eight weeks pregnant with right-sided abdominal pain The pain settled and she was discharged taking amylobarbitone sodium (Sodium Amytal) at night for sedation. She required readmission three weeks later with vaginal bleeding, abdominal pain, and vomiting. Amylobarbitone was again prescribed.

Three days after readmission she developed a purpuric scaly rash over the face, stopping at a line round the neck. The rash had appeared after a bout of vomiting. She had had a similar rash on two occasions before admission, each time preceded by vomiting. The rash started to fade within 24 hours, but recurred twice after vomiting. Her haemoglobin concentration, white-cell count, platelet count, bleeding time, clotting time, and prothrombin time were normal. Further progress was uneventful.

Purpura of the face and neck associated with vomiting and coughing has been described.1 This patient's rash was itchy, scaly, and purpuric, which suggests there was an eczematous component. The appearance resembled eruptions due to carbromal, in which there is eczema and capillaropathy. Classically these occur on the lower legs. It is possible that the amylobarbitone caused the rash and that the changes in intravascular pressure with vomiting determined its siting on the face and neck rather than the lower legs. -We are, etc.,

MICHAEL BURKE JANET MARKS

Newcastle upon Tyne
Champion, R. H., in Textbook of Dermatology ed. A. Rook, D. S. Wilkinson, and F. J. G.
Ebling. Oxford and Edinburgh, Blackwell, 1972.

\section{Grades of Hypothyroidism}

SIR,-Dr. C. D. Evered and his colleagues (17 March, p. 657) have done a valuable service in reminding us that hypothyroidism is often difficult to diagnose when in a mild degree, and also in confirming that the serum thyroid-stimulating hormone (TSH) level appears at present to be the most sensitive laboratory index of thyroid failure. TSH assay is as yet available only in a few centres, however, and it is probable that measurements of thyroid hormone levels in blood (thyroxine, free thyroxine, or free thyroxine index) will continue to be the mainstay of routine laboratory diagnosis of hypothyroidism in most units for some time yet. Measurement of free thyroxine or a free thyroxine index ${ }^{1-3}$ is thought to give better diagnostic discrimination than serum protein- 